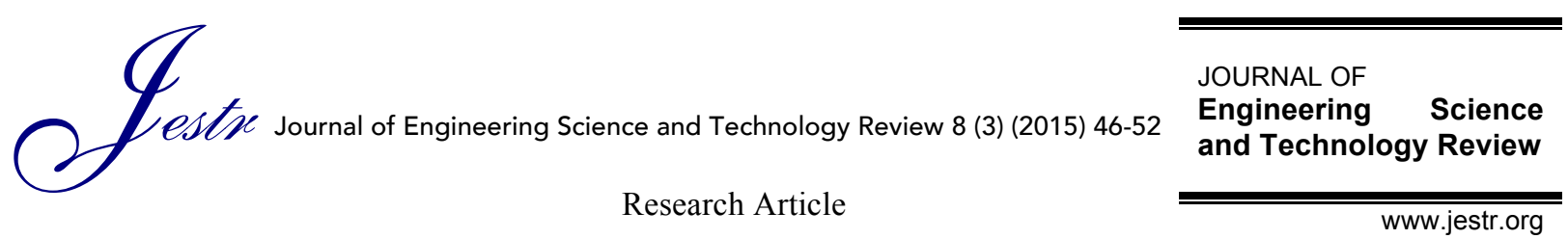

\title{
Concept Design and Development Model of Underground Villas
}

\author{
Xinrong Liu ${ }^{1,2}$, Zijuan Wang ${ }^{1,2^{*}}$, Jun Liu ${ }^{1,2}$ and Zhongping Yang ${ }^{3}$ \\ ${ }^{1}$ College of Civil Engineering, Chongqing University, Chongqing 400045, china \\ ${ }^{2}$ Key Laboratory of New Technology for Construction of Cities in Mountain Area (Chongqing University), Chongqing 400045, China \\ ${ }^{3}$ Department of Hydrology and Water Resources, The University of Arizona, Tucson, Arizona, U.S.A.
}

Received 1 March 2015; Accepted 3 August 2015

\begin{abstract}
With the rapid development of society, modern buildings have been consuming excessive amount of energy and resources. Eco-friendly building is going to be the leading style of architecture in the future. Underground villa, as a type of energy efficient architecture, has widely drawn humans' attention. However, Chinese are still at an exploratory stage in terms of the development of underground construction. This paper describes several typical underground villas in western developed countries; briefly states the advantages and shortcomings of underground villas; discusses the design of style-planning, inner-space design, lighting and ventilation, and waterproof and fireproof of underground villas; also puts forward how to improve the living environment of underground villas. Besides, the paper suggests an innovative concept of underground living that best suits China's market based on the merits of underground villas and the analysis upon China's traditional cave-house. In addition, it roughly analyzes the prospect of this innovate style of dwelling in China.
\end{abstract}

Keywords: underground villas, earth sheltered building, environmental design, energy saving, cave dwelling

\section{Introduction}

Nowadays, humans have been strengthening the study on energy and environment. As a result, we have realized the importance of sustainable development [1]. In some foreign countries, semi-underground villas have drawn people's attention as they are energy economical and noise insulated, and can help improving the functionalities of the building itself. People can make full use of the neighboring resources when building an underground villa so that it becomes more integrated with the natural landscape around it. In other words, underground building can become a part of the culture of nature. It can be seen as a kind of ecological architecture. Technically, underground villa means a villa that is constructed under the ground. Underground architecture has a long history. Troglodytism in the ancient times is a typical style of it. Underground architecture in modern times, especially the underground villas in this study are results of advanced technology, which have not only absorbed the advantages of cave living, but also eliminated the disadvantages of gloominess and dampness.

In some western countries, underground villas are outcomes of limited land resources. Continuously long-term urbanization has occupied most of the usable land resources. Accordingly, the governments of these countries have issued very strict policies on natural land resources protection. As a consequence, it is almost infeasible to construct a completely new building on a Greenfield site. Therefore, underground

* E-mail address: 346484339@qq.com ISSN: 1791-2377 @ 2015 Kavala Institute of Technology. All rights reserved. villa shows the breakthrough and innovation of the way human beings think of buildings. Not only does this idea help protecting our environment, but also satisfies people's psychological needs of getting away from the urban noise and living close to the nature. American architect, William Morgan, is well known for his study on the relationship between architecture and natural landscape in the 1960s. He designed various styles of modern cave-living based on his research on traditional building foundation and the North American Indians' tribes, which amazed the public because of their mysteriousness. Underground villas are invisible to the exterior, on the other hand, of which the interior combines high technology and comfortableness. What's more, the harmonization between human living and the nature is achieved; humanity is well considered and applied. As a matter of fact, underground villa has more and more become an option for the wealthy as their so called "customized luxurious house", [2], [3], [4], [5].

\section{Typical cases of underground villas}

\subsection{Full underground villa}

There are a number of typical underground villas in foreign countries, each of which has its own unique characteristics. Thus, everyone is not able to be duplicated as if it has been vitalized [6], [7]. The following are some representational works of different architectural styles.

\subsubsection{Single underground villa}

Holmewood House (figure 1) is a villa designed by Robin Partington in London, Great Britain. It is built under a piece of land of nearly 150 acres covered by farm fields, grazing 
grass, and beech trees. The roof of the villa is solid enough to bear the pressure from lawns, soil, and driving tractors. With its transparent ceiling, everything on the roof is visible to the interior of the house, which is why the roof is called "green roof". In the center of the house is there a patio. The floor of the house is movable which can be turned into a swimming pool in seconds with a touch of button. The inner wall is completely built with carefully selected French lime stone. Besides, the power switches and media control system boards are made according to the texture of stone. By splicing the stones and the boards together seamlessly, the wall itself is entirely waterproof. Thanks to its flexibility, this underground villa as a private dwelling has been used to hold various kinds of conferences.

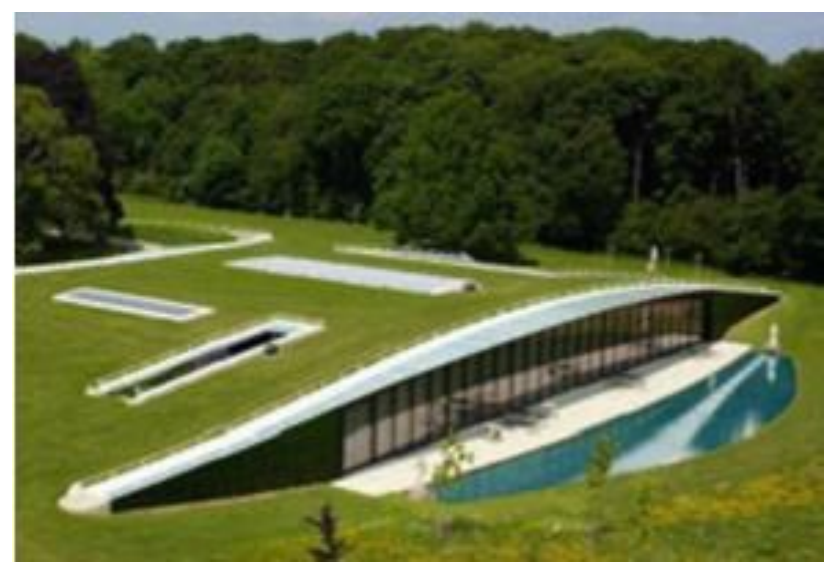

Fig.1. Holmewood House villa [19]

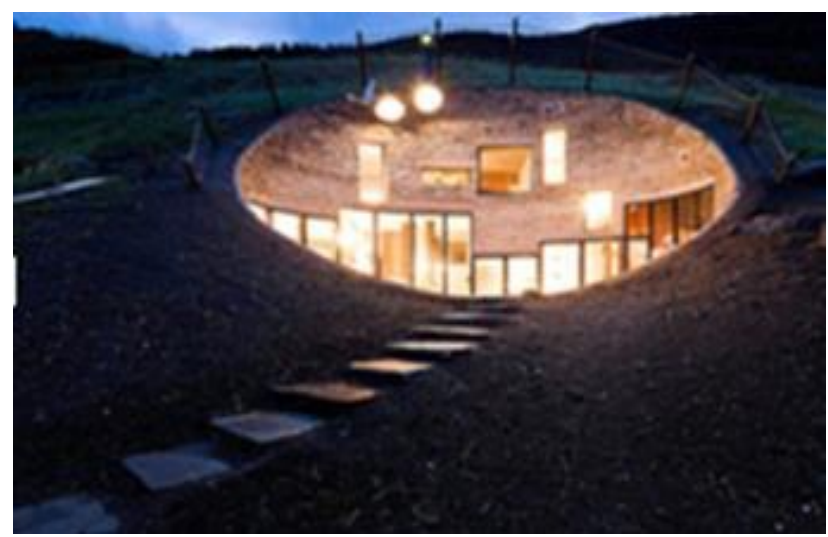

Fig.2. Villa Vals villa [19]

Villa Vals (figure 2) is located under a slope on the Alps with an altitude of 1250 meters, in the southeast of Switzerland. As swiss law expressly stipulates that modern architecture is prohibited on any mountainside, the architects turned to building the house underground by drawing on the experience of Upper Cave Man. The building, as result, has become a part of nature and blends itself well to its surrounding vegetation and the sky. The whole house is mainly built with stone and wood. The opening was designed as a sunken sphere, in order to make the patio more spacious. On the other hand, they excavated a subterranean tunnel for entering and exiting, so that there would not be any man-traces on the slope.

\subsubsection{Combined Underground Villas}

The idea that Earth Home can be designed flexibly based on the thoughts of designers and on the needs of owners has been widely accepted. Estate Lättenstrasse (figure 3) in Dietikon, Switzerland designed by Peter Vetsch is a typical representative of Earth Home. This underground building is formed of nine houses which are joined together with stairs. It is well suited to the terrain around it, which makes it more protected from rain, wind, extreme temperatures and abrasion compared with traditional buildings on ground.

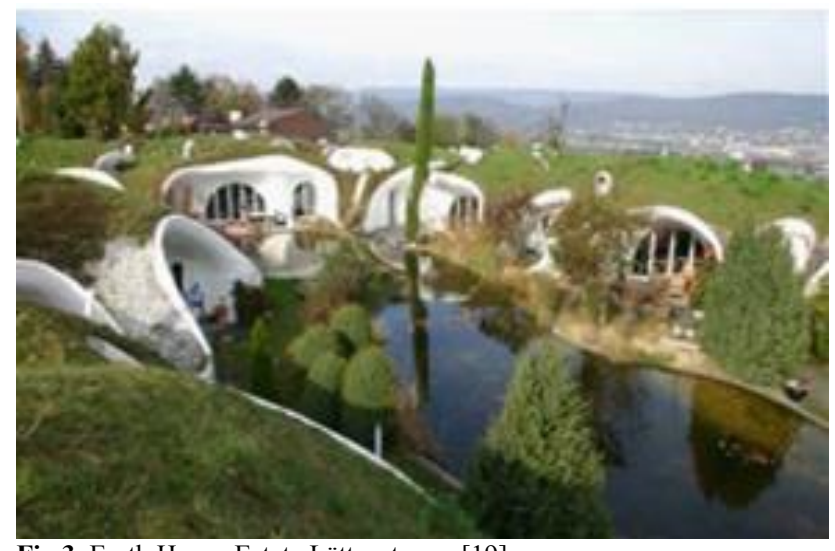

Fig.3. Earth House Estate Lättenstrasse [19]

Flower Petals in Bolton, U.K. (figure 4) is a rural ecofriendly underground villa built under a hillside. Its roof is connected to the surrounding lawns seamlessly. A certain gradient was designed in order to obtain a good view of the outside in the villa below the ground. Flower Petals is composed of one central house and six functional houses. As a modern residence equipped with high technology, the villa generates electricity with wind power and solar energy, and operates the heating system with pumps, leading to zero carbon emission. Unlike the traditional quadrate homes which are built with all bricks and concretes, Flower Petals is so eco-friendly that mankind is able to live closer to the nature, which makes it stand out.

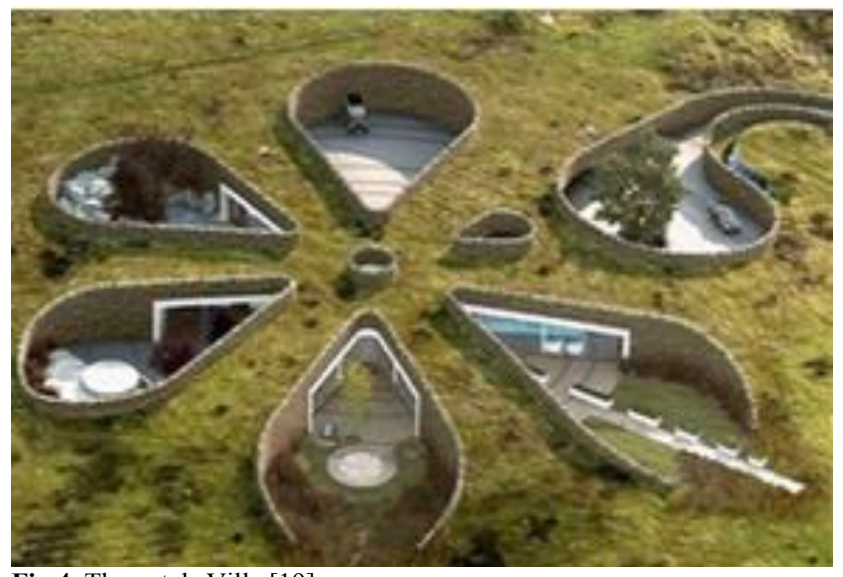

Fig.4. The petals Villa [19]

\subsection{Semi-underground villa}

Sedum House (figure 5) is a semi-underground residence designed and constructed in North Norfolk, U.K. by architect Tom Ground. The bedrooms and some other sections of the house are underground, and the roof is covered by vegetation. The glass wall on the front side is designed to let in enough daylight to the indoor side, the illuminating system on the ceilings being designed to light the house at night. The ground over the roof is highly 
waterproof. Besides, it also contributes to the solidness of the whole structure of the house.

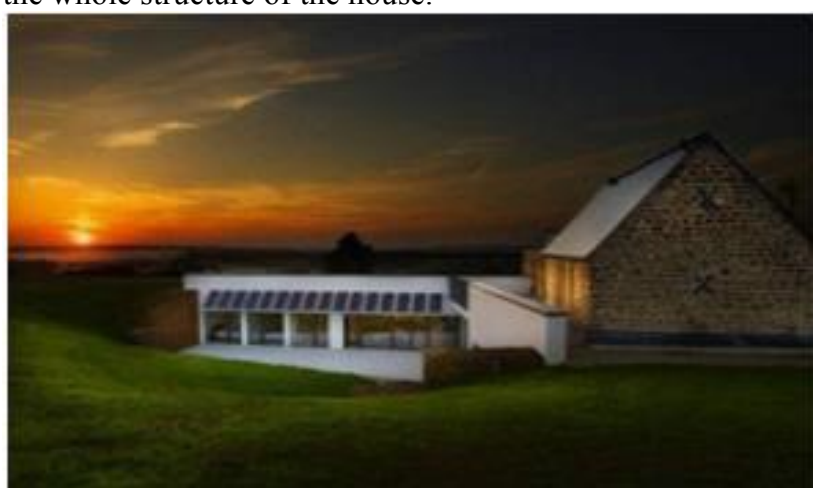

Fig.5. Sedum House villa [19]

A-cero is a famous architect who designs and builds private residences for the wealthy. The biggest merit of Acero's villa is that it is hidden under a hillside on which planting is possible. Using solar energy, the house is certainly eco-friendly. On one side of the slope, grey concretes with the surrounding green plants result in distinct visual impacts. In addition, the green plants that spread all the way to the roof can absorb severe sunshine, and can thus create a suitable indoor temperature environment. Also, there is a unique rain water spreading system on the roof so no water would be collected that may cause any problem. As a residence, the indoor structure of the building was designed to be sloping with clear edges and angles, except for the bedrooms and the living rooms. What's more, a swimming pool makes the living experience in the villa more pleasant. Reinforced concrete in contrast with glass, layers of different natural materials such as stone, wood and cement, and the unique construction style all contribute to the attractiveness of this villa. Additionally, the underground home amazingly includes all kinds of functions that may be needed in life, such as parking garage, laundry room, dining room, kitchen, washroom, office, playroom, study, home theater and so forth.

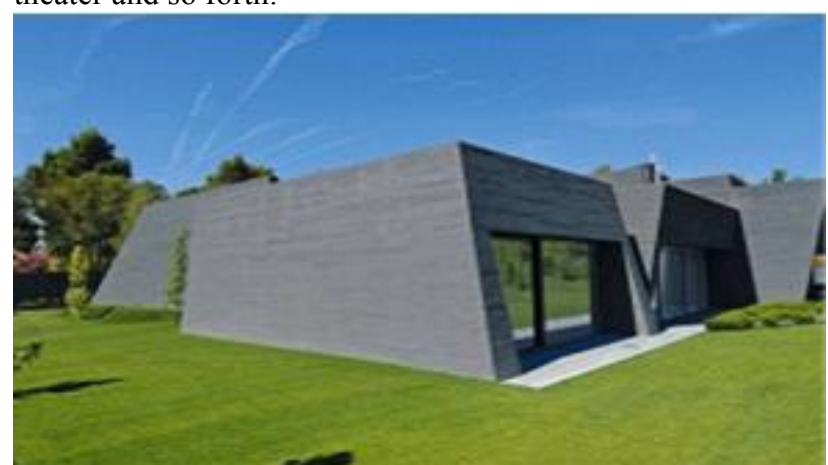

Fig.6. A-cero Modern villa [19]

\section{Advantages of underground villas}

\subsection{The necessity of the development of underground villas}

As its name implies, an underground villa is a villa that is wholly buried under the ground. It is a kind of earth sheltered building. (Figure 7 ) shows the cross section of a typical underground villa. Only the facade of the building is exposed to the outside, which is either a glass-made wall or an ordinary wall with a lot of windows. Thus, the sunlight can shine through the glass or the windows, energy from the sunlight being reserved. On cloudy days, the energy would be radiated to the inner space. This way, non-renewable resources are effectively saved.

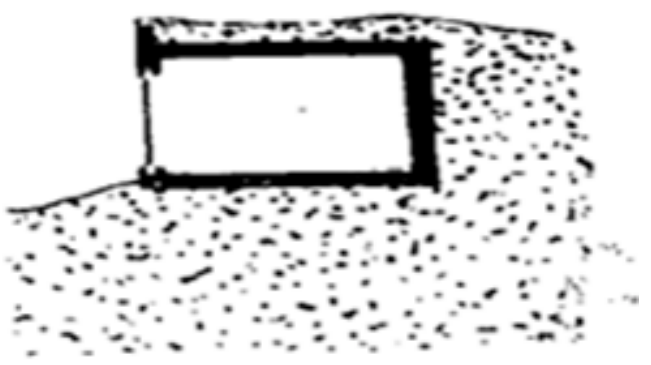

Fig7. Cross-sectional view of the underground villa. Self-Elaboration

A luxurious underground villa usually has stunning appearances and is enhanced with advanced technology. More of its advantages are listed below.

(1) It is environmental friendly.

Urban sprawl occupies extensive farmlands, cultivated lands, forests and so on, which, as a result, destroys ecological balance and pollutes the environment. On the contrary, building underground villas only vertically uses the room below the ground. By so doing, humans can minimize the degree of destroying to our environment. Consequently, flowers, plants and trees, and fishes, birds and insects are better protected.

(2) It is energy economical.

Humans are faced with a severe problem: we have been consuming a tremendous amount of energy, especially when cooling our homes in summer and heating our homes in winter. Soil is a natural air conditioner, so if we build our homes underground, it helps keeping the indoor temperature very steady. Therefore, it is cool in summer and warm in winter. The structure of underground homes is usually rationally designed so that adequate sunlight can shine into the inner space. By applying certain technology, any residual solar energy would be restored, and would be released to warm the house when winter comes. As investigations suggest, underground houses can help saving petroleum by from $60 \%$ to $80 \%$ compared with above ground buildings. Our cost on energy consuming could be largely reduced.

(3) It is quiet and peaceful.

Most of the underground villas are built in the open country where there are adequate natural resources. Besides, underground homes are normally much more noise resistant, which makes them quiet enough for resting and working. In areas close to highways, bus stations, airports, factories, and the like, underground villas are apparently better choices in terms of noise insulation.

(4) Land resources can be effectively saved.

By building villas below the ground, we can save a lot of land. Besides, the roofs of underground villas can usually be afforested or be used as plazas. In mountain cities, buildings can be situated at the foot of the hills, the hill itself serving as a suspended wall of the building. Thus, the buildings are combined into their surroundings without taking too much land. The method can be adopted to solve the problem of limited land resources in urban areas.

(5) It is safe and reliable.

Underground villas are earthquake resistant and fireproof. They also can serve as shelters for people in case of wars. According to researches, in earthquake-prone regions, underground constructions get much less damage from earthquake than aboveground ones. In cases of fire, fire would normally be blocked by the constructions therefore 
would not spread to the neighborhoods. In addition, because the entrances of underground homes are generally concealed, the possibilities of invasions can be reduced.

(6) It is much more durable.

Underground villas are more durable as time goes by, because they are hardly damaged by wind, rain, thunder, and lighting. Beside, water pipes would not get frozen or even cracked in winter, related repairing costs being saved. All in all, underground home is a way of sustainable development for human beings.

\subsection{Problems and considerations}

(1) People's first impression of underground home is that it is damp, dark and even charnel inside, because of which most of us are not willing to live underground. In cities, only the underclass would tend to choose basements as their homes. These concerns can not be more understandable. In order to build a luxurious underground villa of high qualities, common problems for underground constructions such as lighting, ventilation and dehumidifying are to be solved at first. Effective lighting and ventilation can be achieved through ingenious design of the building structure. Normally, in so doing, only natural resources would be used, and thus it is energy efficient. Compared with traditional electricitypowered system, natural energy does not reply on materials and machines. As long as efficient lighting and ventilation is available, there would not be any problem to dehumidify the inner space of underground homes.

(2) Different constructing methods should be considered based on the earth conditions in different regions. Accordingly, the costs would vary. The building cost of underground villas consists of initial-stage cost and operational cost. Generally, the initial-stage cost is higher than that of above-ground buildings. Despite, there is no associated cost on land. In addition, mineral materials in the excavating process can be put on the market.

\section{Inner environment of underground villas and the design of fireproofing and waterproofing}

\subsection{Factors affecting the inner environment of underground villas}

Modern underground residence is ought to satisfy humans' basic needs in daily life, in addition to which, a pleasantly comfortable living environment should also be available. In order to strengthen underground villa's promotion value in domestic market, architects have to make efforts to improve its living environment. Hence, that is ought to be the number one principle on every building stage, i.e. the scheming stage, the design stage, and the on-site construction stage.

Main factors that affect the environment of underground villas are shown in table 1 . Underground villa's living environment is the unity of information, energy and material, which actually interpenetrates each other. Among these factors, stream of people, stream of objects, light and electricity are physical factors; visual and auditory sensation are sensatory factors

Table 1. Factors that impact the design of underground villa's environment. Self-Elaboration

\begin{tabular}{lc} 
Factors & Optimum state \\
\hline Space & Unification of physical and psychological space \\
Sense & Gradually gaining knowledge of unknown environment \\
Nature & $\begin{array}{c}\text { Integrating underground environment into the natural } \\
\text { environment }\end{array}$ \\
Design & $\begin{array}{c}\text { Create a living environment that is similar to that of } \\
\text { aboveground villas }\end{array}$ \\
\hline
\end{tabular}

\subsection{Style-planning and style designing of underground} villas

Appropriate layout enables underground home to better fit its surrounding environment. Besides, people's mental needs would also be better met.

Differentiate the height of each function room, to strengthen the underground home's fluctuation and mysteriousness. Thus, people's willingness to reside would be aroused.

Although it is built below ground, the environment above underground villas should still be beautiful. Otherwise, it would be less meaningful to open up the project. Appropriate options include lawn areas in suburban districts and golf courses. By building villas underground in these areas, we would be able to see the scenery outside the villas.

The inner structure of underground villas would better be more complex than that of aboveground buildings, to avoid being too baldly flat or squared. In order to make it appealing to people, architects have to add as many distinguishing features as possible to underground constructions. For example, by pumping into high-new technology, we are able to make underground villa a new style of modern residence.

Make full use of the space above the underground villas. By sharing space with aboveground world, we are able to attain a strong sense of expanded three-dimensional space, which would effectively lessen our depressive sense.

\subsection{The inner-space design of underground villas}

A luxurious underground living villa should give people an impressive visual impact. The sense of space is the most important factor when designing a villa's living environment. When we talk about the space of a unique type of architecture, i.e. underground home, it means not only the physical space, but also our mental sense of the space.

Humans have been used to living aboveground. Therefore, people need to overcome a psychological obstacle when transferring to underground homes. In order to reduce people's feeling of depression living underground, architects are ought to strengthen the sense of space when designing an underground home of the same size of an aboveground one. As researches have suggested, people's requirement for open windows can be measured by the following equation:

$$
S_{P}=C L^{\alpha} R^{\beta} \omega^{\gamma}
$$

$C$ is a constant; $\alpha=0.2 \sim 0.4 ; \quad \beta \approx 1 ; \quad \gamma=0.3 \sim 0.5 ;$ $L=25 \sim 1600 / \mathrm{x}$ (the indoor illuminant intensity); $\mathrm{R}$ is the capacity of a room; $\omega$ is the projection ratio of the $3 \mathrm{D}$ angle of a window's opening on humans' eye. Researches also conclude that when SP approximates $100,50 \%$ of people are satisfied; when SP approximates $200,100 \%$ of people are satisfied. Based on the equation above, we can come to a conclusion that the capacity of the room and the size of the windows are the most two significant factors affecting people's sense of space.

\subsection{The design of lighting and ventilation}

It is a waste of energy if we employ artificial machines for lighting and ventilation in the long run. Therefore, to save energy, we should take full advantage of natural conditions to ventilate underground constructions. We can set up a sunken patio for an underground villa. The patio then can serve as a medium that assists lighting and ventilating the 
villa. Besides, vegetation can be planted on the roof to screen out the sunlight in summer.

The effectiveness of ventilation depends on the villa's orientation, its layout, and the position and size of the vent. The direction of wind pressure should be identical to that of heat pressure at the vent. The position of the vent should be flexibly altered according to the local climate and wind direction in different seasons. The purpose is to effectively ventilate the inner space and also to make the villa cool in summer and warm in winter.

Natural lighting means passively making use of solar energy to light the house. Usually underground villas can be built with side-windows, skylights or patios. Besides, the roof and the under-earth part of the construction should be designed in a staged mode. For half-underground villas and these with sunken courtyard, there should be as many windows as possible on the north and south walls. Equip the windows with specially designed baffle-board system to repeatedly reflect sunlight, so that it is able to reach the very deep and far areas. Consequently, lighting will be more effective in underground buildings. If natural lighting does not meet the basic needs because of the limitations of the local environmental conditions or the building's structure, we can apply modern lighting equipments such as light pipes and optical fiber or modern illuminating technology to make up for the insufficiency.

\subsection{Design of waterproof and fireproof \\ 4.5.1 Design of waterproof}

The external cause for dampness is the humidness of the air while the immanent cause varies. Leaking coverage layer above the building, residual water from the construction process and ineffective moisture dispersing system all belong to immanent cause. The coverage layer is ought to be as flat as possible; otherwise, there is a high possibility of leakage in rainy seasons.

Waterproofing an underground construction is apparently more in connection with the immanent cause mentioned above. Technically, it means to prevent rainwater and damp air from entering underground villa. Specifically, the building itself has to be joined to the original side slope and the covering vegetation layer seamlessly. Seamlessness should be considered as the most important principle in the construction process, which means waterproof materials need to be carefully selected. Moisture dispersing is to reduce or eliminate the humidity using natural powered machines, which certainly requires energy. Hence, in order to save energy, we should mainly focus on waterproofdesign. The procedure of underground building's waterproof can be divided in to three stages: general plan, constructional design and system layout.

\subsubsection{Design of fire prevention and emergency escaping system}

One of the most distinguishing features of underground villa is that it is almost closed to the outside world. In case of fire, insufficient exits would hinder people from escaping. Therefore, as much caution as possible should be taken to prevent fire in the first place. In case the villa is on fire, alarm should be sounded immediately to warn people to escape and the fire should be extinguished as soon as possible in order to minimize the property loss. In order to increase the likeliness of successful escape, we should simplify and standardize the vertical structure as well as the horizontal layout, with the villa's mysteriousness being sacrificed. In this way, people would have a more distinct sense of direction when escaping from fire. In addition to that, it needs to be taken into consideration that the escaping direction underground is opposite to that in an aboveground building when dividing fire prevention and smoke blocking areas. An advanced disaster prevention system is very essential to modern constructions as it can instantly inform people of the disaster so that people would have more time to escape. For underground residence and especially luxurious underground villa, the fire-sensor and alarming system needs to be effective and accurate to the maximum. Additionally, monitors should be properly set up which would help the firemen better know the situations in various areas.

\section{Customize the development mode of underground villas for domestic market}

\subsection{A brief introduction of traditional cave-house}

Cave-house is a kind of arched cave-living house for people in loess regions of China. People excavate out the house by making use of the solidness of loess. Cave-house is the landmark architecture on loess plateau. It is fireproof, noise proof, and is cool in summer and warm in winter [8]. It is a perfect construction style that is suited to local conditions. Chinese cave-house has been through three phases which are half-crypt style in Zhou Dynasty, full-crypt style in Qin Dynasty and earth cave at modern times. The front wall of earth cave then has been built with stone or even colorful ceramic tiles. The structural model of cave-house can be divided into three categories according to natural environment, physiognomy and local natural conditions.

\section{(1) By-cliff cave-house}

It is also called cliff-cave-house (figure 8) which is normally a cave that is constructed by a cliff or a ravine. The houses are curve shaped or arrayed in a line by the hillside, which means they are nicely suited to the natural landscape. If the hillside is high enough, the cave-house can be built with more than one floor.

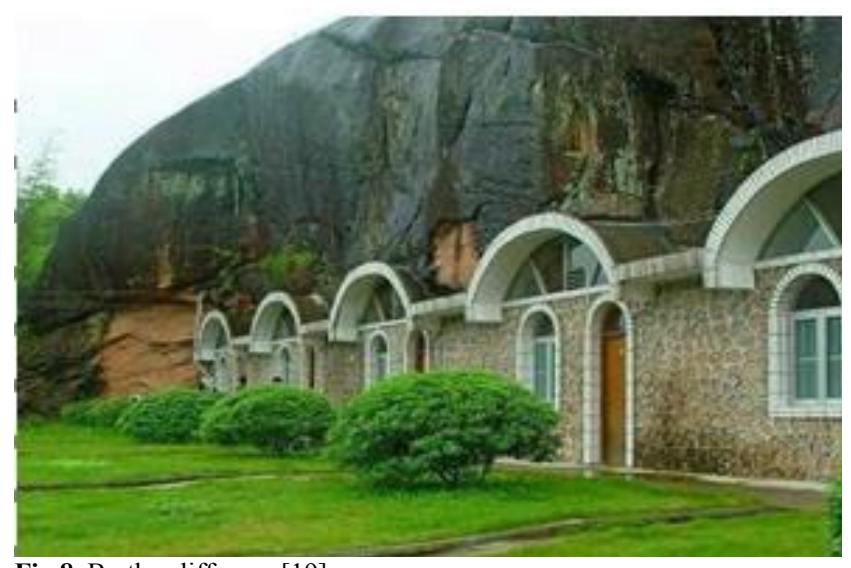

Fig.8. By the cliff-cave [19]

\section{(2) Sunken cave-house}

Sunken cave-house (figure 9), in other words, earth cave-house, scatters mainly on the loess plains where there is no hillside or cliff. A big hole is dug firstly, after which four caves are dug out from four sides around the big hole. Sunken cave-house is just like a sunken siheyuan (also known as "Chinese quadrangle"). 


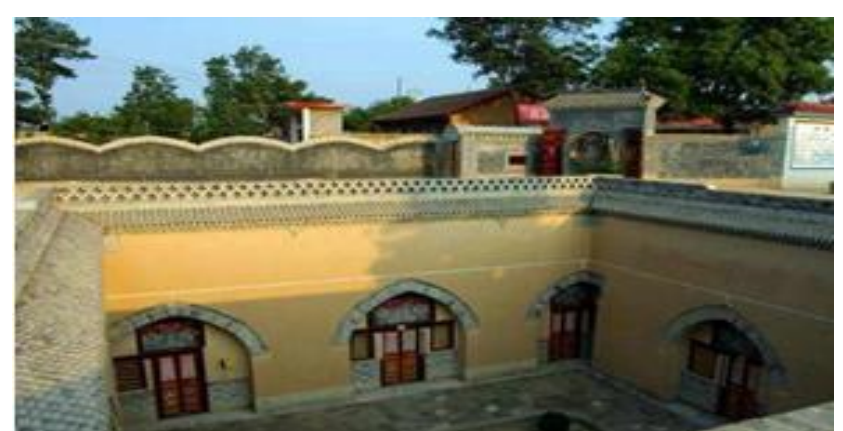

Fig.9. Sunken cave [19]

(3) Detached cave-house

Detached cave-house (figure 10), which is also named bracing cave-house, is a type of earth sheltered architecture. It varies a lot in terms of its style, including soil-arched style, brick-arched style, stone-arched style, and wood-arched style. In addition, detached cave-house can be either singlestorey or multi-storeyed.

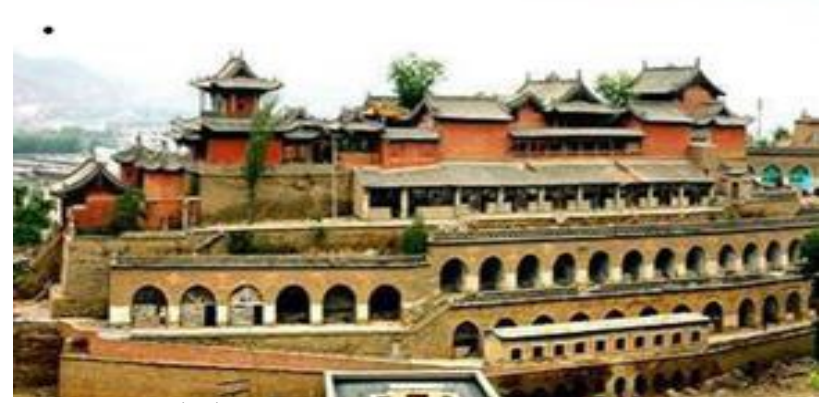

Fig.10. Detached cave [19]

\subsection{Combination of cave-house and underground villa}

In China, The development of underground villa should be undertaken using the experience of cave-house for reference. We should combine the architectural theory of cave-house with modern technology, so that we are able to come up with a fresh style of underground building that indeed satisfies people's needs. As we do not have a thorough understanding of traditional cave-house, most of the modernists, especially the young people, are not willing to settle down in cavehouses. Cave-house has been viewed as the symbol of poverty, so it has been more and more unaccepted in the market as time goes by [9]. However, in fact, the traditional Chinese sunken cave-house is similar to those luxurious underground villas abroad in their architectural concepts and many other ways, except that cave-house is only a simple earth house while those underground villas are highend architectures abounding in modern technology and humanity. People recognize the value of underground villas and are willing to move down there because those villas have become a symbol of richness and high social status.

In order to become highly marketable, any kind of residential architecture has to be cost effective, functional and widely acceptable. It is very feasible to develop underground villas based on our experience from the traditional cave-house. As China is a developing country, expenses on constructional design and personnel, and cost on land is much lower than that in a developed country. Therefore, it is cost effective to build underground villas in our country. Besides, the rich have been becoming an increasingly large portion of China's population, which means a number of people can afford pursing a more unique residential style. So we can gradually open up residential complexes of half-underground villas and full-underground villas to meet these rich people's demand [10].

In order to minimize earth cave-house's deficiencies of roof falling and crack, we need to apply advanced and ecological technology when building underground villas. Take compacted soil as an example, it is not only solid enough and is waterproof, but also is more cost effective than reinforced concrete.

We can build eco-friendly underground villas with patiolighting system referring to sunken cave-house, and build half-underground villas referring to detached cave-house [11], [12], [13], [14]. It is an innovative way of utilizing the inheritance from our ancestor. Although underground buildings' constructional cost is higher than that of regular aboveground buildings, they are more energy efficient, ecofriendly and sustainable in long term. In many African countries, the mechanism of sunken cave-house has been applied to modern underground constructions. Alike, we can certainly innovate on our traditional cave-house by applying new ideas and techniques, to invent a unique Chinese style of underground villas. Once this constructional style is available for coping and referring to, it would be widely adopted for certain [15], [16], [17], [18].

\section{Conclusions}

Based on China's current economic situation, we can progressively develop underground villas in regions that meet the conditions. It is believed to be the development orientation of architectures to build homes underground in future. Entirely underground villas are more feasible and suitable in suburban areas while half-underground villas would be more marketable in urban areas. The type of construction only vertically takes space from underground instead of expanding horizontally. In this way, we are able to decrease the floor space of the buildings; as a result, a large amount of land would be saved. If we start moving to underground homes and replacing the current above ground buildings with forests and lawns, ecological balance is in prospect.

\section{Acknowledgements}

The Research Fund of Ministry of Education for the Doctoral Program of Higher Education with the theme of Macroscopic and Microscopic Research on the Damage Mechanism of Rock Deterioration under the Effect of Drywet Cycle (20120191110039).

\section{References}

1. Zhang J, Jiang Y, Hu B, "The urban derground space sustainable development pattern initially searches-take the TongZhou new town core area derground space plan research as the example", CCES, 2010. (in Chinese)

2. Xue Y-B, "Floating place-The uncertain meaning of place in a postmodern context", [Ph.D.thesis], Beijing: Central Academy of Fine Art, 2007. (in Chinese)
3. Sheng J, "An reflection and analysis on the values system of landscape architecture", [Ph.D.thesis], Beijing Forestry University, Beijing, China, 2012. (in Chinese)

4. Liu Q-B, "Study on synthetic assessment to green residential quarters", [Ph.D.thesis], Xian University of Architecture and Technology, Xian, China, 2005. (in Chinese) 
5. Chin C-Y, "A study on the connection between landscape and ecological aesthetic", [Ph.D.thesis], Southeast University, Nanjing, China, 2006.(in Chinese)

6. Chen Y-H, "A research on the impact of the western contemporary art on lnterior design", [Ph.D.thesis], Tongji University, Shanghai China, 2008. (in Chinese)

7. Chen X, Song G-J, "The Comparison of The Development of Ecological Architectures in Germany and China". Industrial Construction, 39(04), 2009, pp.37-40. (in Chinese)

8. Liu H, "The regional small watershed units of human settlements and the security models on the loess plateau", [Ph.D.thesis], Xian University of Architecture and Technology, Xian, China, 2005.(in Chinese)

9. Li Y, "Study on the rural residential environment of ecological fragile areas in Shanxi Gansu Ningxia provinces", [Ph.D.thesis], Xian University of Architecture and Technology, Xian, China, 2011.(in Chinese)

10. Jiang L, "Cultural evolution and value collision in urban historic heritage conservation”, [Ph.D.thesis], Tongji University, Shanghai, China, 2006. (in Chinese)

11. Zhou H, "The researches on sustainable capacity of the large-scale public projects on the basis of the ecology", [Ph.D.thesis], Southeast University, Nanjing, China, 2006.(in Chinese)
12. Miao J, Chen J-P, "A miraculous flower of traditional folk houseDooryard-cave-houseand courtyard of containing environment and saving energy". Chinese and Overseas Architecture, (2), 2006, pp. 42-44. (in Chinese)).

13. Liu W-J, Miao X-P, Cheng B-Y, "Brief Analysis of Energy Conservation Design of Underground Buildings". Industrial Construction, 39(2) ,2009, pp.67-41.(in Chinese)

14. Di Cristofalo, S. Orioli, S, "Thermal behavior of 'Scirocco rooms' in ancient Sicilian villas". Tunnelling and Underground Space Technology, 4(04), 1989, pp. 471-473.

15. Xing Q-Y, "Energy- saving Effect of the Temperature and Humidity Independent Control System and Its Project Example". Building energy efficiency, 39(5), 2011, pp.11-15.(in Chinese)

16. Liu X-P, "Finite element method numerical simulation of forest roots reinforcement", [Ph.D.thesis], Beijing Forestry University, Beijing, China, 2008.(in Chinese)

17. Wang L, "Exploration of Ecological Architecture and Its Realization Way in our Country". Journal of Jiangsu Jianzhu institutered, (6), 2012, pp. 20-23. (in Chinese)

18. Qu W-B, Liu X-R, Liang N-H, "Consideration of incorporate underground space exploitation and utilization in Chongqing". Chinese eJournal of Underground Space and Engineering, 3(3), 2007, pp. 402-405. (in Chinese)

19. Beverly Jenkins. (2012, February 22). "10 Amazing Underground Homes", ODDEE, Retrieved from http://www.oddee.com/item 98085.aspx. 